\title{
004 \\ Investigation of ergonomic parameters of easy chairs in Moratuwa furniture manufacturing establishments
}

\author{
S A L P Silva and H S Amarasekera \\ Department of Forestry and Environmental Science, University of Sri Jayawardenpura, Sri Lanka
}

\begin{abstract}
Sitting on a comfortable seat helps to relax the body and reduce energy consumption, but on the other hand prolonged sitting slackens abdominal muscles and may cause back ache. Application of medical and ergonomic principles in the design of a seat can maximize advantages and minimize disadvantages in sitting.
\end{abstract}

In Sri Lanka the demand for a furniture depends on the customer perception to comfort and beauty of the product. The present study aimed to find out whether the easy chairs manufactured in the Moratuwa Furniture Manufacturing Establishments were ergonomically designed for the Sri Lankan users.

The investigation was initiated with the identification of easy chair designs in the Moratuwa Furniture Manufacturing Establishments. A representative sample of two popular easy chair designs, the Kulu Putuwa and the Meda! Putuwa, was then selected. The different design parameters of these twc chairs were measured. It was observed that there were differences in the dimensions of the major design parameters of the chairs between companies.

Sri Lanka has no specific standards for designing of furniture. Hence design standards were developed for easy chairs in the present study based on available anthropometric data for Sri Lankan users and other published anthropometric data on seat designs.

The different design parameters of Kulu Putuwa and Medal Putuwa were then compared with those developed ergonomic standard values. It was observed that only the back rest height of the easy chairs was ergonomically acceptable in all the companies surveyed. Seat height, seat depth, seat width and arm rest height were lower than the accepted standard values. Such improper dimensions should result in discomfort and body pain. The angle of rake and angle of tilt, which indicate the inclination of the back rest, were significantly lower in the sampled chairs. The inclination of the back rest was lower than the required $115^{\circ}-120^{\circ}$, which should result in low back stress and static muscular tension, which may lead to development of back injuries.

In order to improve the ergonomic parameters of the Medal Putuwa, a prototype chair was designed. Seat height, seat depth, seat width, arm rest height, of the prototype char was lower and it had higher angle of tilt and angle of rake. The designed prototype chair was evaluated against a normal control chair, and the users rated the ergonomically designed chair was much better compared with the control in terms of comfort.

The present study reveals the need for Sri Lanka to have specific standards based on the body sizes of users, for design of furniture. This will enable the production of ergonomically correct and aesthetically acceptable quality furniture in Sri Lanka.

\section{5 \\ Estimation of above ground biomass of forest trees using dbh as a single parameter \\ I D Welivita and S M C U P Subasinghe \\ Department of Forestry and Environmental Science, University of Sri Jayewardenepura, Sri Lanka}

Forests in Sri Lanka contribute to the mitigation of climate change through sequestrating a net amount of carbon dioxide and also maintaining carbon stock as biomass. Total tree biomass comprised of above ground and below ground biomass of trees. This paper presents a methodology developed to estimate individual tree above ground biomass using allometric relationships. The advantage of this method is that the above ground biomass per unit area can be determined by estimating these values for different species separately within that area. The present study was conducted in Yagirala Natural

Proceedings of the International Forestry and Environment Symposium 2006 of the Department of Forestry and Environmental Science. University of Sri Jayewardenepura. Sri Lanka 